\title{
Bile Acid Transformation in Gnotobiotic Mice Associated with Human Intestinal Flora
}

\author{
Seiko Narushima, ${ }^{1}$ Kikuji Itoh, ${ }^{1 *}$ Kazuo Kuruma ${ }^{2}$ and Kiyohisa Uchida ${ }^{3}$ \\ 'Laboratory of Veterinary Public Health, Graduate School of Agriculture and Life Science, The University of Tokyo, Bunkyo-ku, Tokyo \\ 113-8657, Japan \\ ${ }^{2}$ Shionogi Research Laboratories, Toyonaka, Osaka 561-0825, Japan \\ ${ }^{3}$ The Cell Research Foundation, Chuo-ku, Osaka 541-0045, Japan \\ Received for publication, March 26, 2002
}

Bile acids are transformed by intestinal microflora. Secondary bile acids including deoxycholic acid and lithocholic acid appear to show a strong correlation with colorectal cancer. However, the role of intestinal bacteria in the transformation of bile acids in vivo is still not clear. We attempted to evaluate which bacterial groups are responsible for bile acid transformation in vivo. First, we orally inoculated germfree (GF) mice with human intestinal bacteria that have the ability to transform bile acids in vitro, and showed that it is not necessarily true that bacterial transforming ability of bile acids in vitro is reflected in vivo. Then GF mice were orally inoculated with human fecal dilution or various components of human feces. In the cecal contents of ex-GF mice associated with human fecal dilutions of $\mathbf{1 0}^{-2}$ or $10^{-6}$, or the anaerobic growth from a dilution of $10^{-6}$, free-form bile acids accounted for more than $80 \%$ and DCA for about $20 \%$ of total bile acid. When GF mice were associated only with clostridia, free-form bile acids made up less than $40 \%$ of total bile acids, but the percentage of secondary bile acids was the same as in the other groups. These results indicate that predominant bacteria-mainly bacteroides in human feces, which are the main bacterial group for deconjugation of bile acids-and clostridia may play an important role in $7 \alpha$-dehydroxylation of free-form primary bile acids in the intestine. The combination of five strains of bile acid-deconjugating bacteroides and five strains of bile acid $7 \alpha$-dehydroxylating clostridia isolated from ex-GF mice converted tauro-conjugated cholic acid into DCA both in vitro and in the intestine. This GB mouse model should be useful in studies of bile acid metabolism by human intestinal bacteria in vivo.

Key words: cecal bile acids; ex-germfree mice; gnotobiotic mice; human intestinal bacteria

\section{INTRODUCTION}

In humans and animals, intestinal flora are indispensable for bile acid transformation. Bile acids in humans are synthesized from cholesterol in the liver and conjugated to either glycine or taurine. They are secreted into the small intestine as a component of bile and more than $90 \%$ of the bile acids are reabsorbed mostly in the ileum and returned to the liver via the portal blood. The rest of them enter the large intestine and the primary bile acids, cholic acid (CA) and chenodeoxycholic acid (CDCA), are deconjugated and $7 \alpha$-dehydroxylated to deoxycholic acid (DCA) and lithocholic acid (LCA), respectively. There are many reports that implicate the correlation between colorectal cancer and secondary bile acids in vitro $(34,48)$ and in animal studies $(35$, $39,40)$. In epidemiological studies, it is reported that fecal $7 \alpha$-dehydroxylase activity in colorectal cancer patients was significantly higher than that in controls

*Corresponding author. Mailing address: Laboratory of Veterinary Public Health, Graduate School of Agriculture and Life Science, The University of Tokyo, 1-1-1 Yayoi, Bunkyo-ku, Tokyo 113-8657, Japan. Phone: +81-35841-5476. Fax: +81-3-5841-8188. E-mail: akikuji@mail.ecc.u-tokyo.ac.jp
(30). It is essential to understand which bacterial groups are responsible for bile acid metabolism in vivo in order to control bile acid transformation in the intestine.

Deconjugating activity of conjugated bile acids is widely observed in many kinds of intestinal bacteria $(1,31,44)$, especially in the predominant intestinal bacteria. $7 \alpha$-dehydroxylating activity has also been reported in certain groups of intestinal bacteria (5). However, the results for some of the species are contradictory. Some reports indicate that bacterial strains of Bifidobacterium (3), Bacteroides (3) and Lactobacillus $(13,32)$ showed $7 \alpha$-dehydroxylating activity. In contrast, other groups showed negative results for the activity of Bifidobacterium strains $(11,45)$, Bacteroides strains (16, 42), or Lactobacillus strains (7, 45). Only certain strains belonging to Eubacterium and Clostridium have been specifically reported $(2,10,15$, 19, 43). Many reports indicated that the difficulties of isolating $7 \alpha$-dehydroxylating intestinal bacteria arise from the small populations of these bacteria in the intestine $(18,47)$. However, most of the primary bile acids in the intestine are deconjugated and subsequently transformed into secondary bile acids. The precise 
mechanism of transformation of bile acids by intestinal bacteria in the intestine is still unknown.

Although we inoculated human intestinal bacteria with the ability to transform bile acids in vitro into germfree (GF) mice, only a small amount of secondary bile acids was observed in their cecal contents. These data indicate that bacterial transforming ability of bile acids in vitro is not necessarily reflected in vivo (37, 38). Therefore we produced various groups of ex-GF mice associated with human fecal dilution, with anaerobic growth from a dilution of $10^{-6}$, or with only human fecal clostridia (36). The aim of our study was to clarify which bacterial groups harbored in the human intestine are responsible for bile acid transformation in the intestine, and also to produce a good gnotobiotic (GB) mouse model for the analysis of bile acid metabolism by intestinal bacteria in vivo.

\section{BILE ACID TRANSFORMATION BY HUMAN INTESTINAL BACTERIA IN VITRO AND IN VIVO -GNOTOBIOTIC STUDY-}

There are several reports of establishment of gnotobiotic mice or rats and evaluation of secondary bile acids in their intestines $(6,24,27-29)$. However, in most studies bacteria of animal origin were used, and it is still unclear if bacteria isolated from the human intestine act in the same way as those from animals in vivo. We orally inoculated human intestinal bacteria for which the ability to transform bile acids was confirmed by in vitro screening, and evaluated cecal bile acid composition in the intestine.

In the in vitro assay, Clostridium ramosum strain R18 deconjugated taurocholic acid (TCA) to CA, but did not dehydroxylate or dehydrogenate CA. Eubacterium lentum-like c-25 did not deconjugate TCA, but transformed CA to DCA (30\%) and 7-oxo-deoxycholic acid (7 = O DCA) (10\%). Unidentified Gram-positive rod strain HD-17 (now Clostridium hiranonis) converted TCA to CA and DCA, and dehydroxylated CA to DCA. Clostridium sp. strain M-7 also deconjugated TCA to CA to some extent, but only dehydrogenated $\mathrm{CA}$ to $7=$ O DCA.

Three weeks after inoculation of the bacteria into GF mice, all the strains colonized in the intestine at greater than $10^{8} \mathrm{CFU}$. The predominant bile acids in GF mouse ceca were $\mathrm{CA}$ and $\beta$-muricholic acid (MCA), and all bile acids were taurine-conjugated in the intestine. Freeform bile acids were detected in the cecal contents of gnotobiotic mice associated with deconjugating bacteria, C. ramosum R-18 (above 10\%) or Clostridium sp. M-7 (3.6\%). E. lentum-like c-25 did not form free bile acids. GB mice associated with strain R-18 formed both unconjugated $\mathrm{CA}$ and MCA, while in the cecal contents of GB mice associated with strain M-7, almost all unconjugated forms were in the CA group. The deconjugating activity of bacteria varied in accordance with both bacterial strains and bile acid structures as reported by Chikai et al. (6).

However, GB mice showed the ability to deconjugate only $15 \%$ of bile acids. The results were similar to those of previous reports $(7,14)$ and the rate of deconjugation was lower than that of Kayahara et al. (24), which was more than $30 \%$. Dickinson et al. (7) indicated that deconjugation in vitro did not reflect the potential of deconjugation of microorganisms growing in the intestine. The correspondence of deconjugating activity in vitro and in vivo should be clarified by investigating more bacterial strains.

DCA was observed only in the cecal contents of gnotobiotic mice associated with a combination of deconjugating and $7 \alpha$-dehydroxylating bacteria, i.e. strain R18 and Eubacterium lentum like c-25 (4.3\%) or a combination of strain R-18 and strain HD-17 (1.1\%). $7=0$ DCA was detected in the cecal contents of gnotobiotic mice associated with strain M-7 (1.3\%) or strain R-18 plus strain M-7 (2.4\%). All secondary bile acids detected were in the unconjugated form, suggesting that secondary bile acids may be mainly formed from unconjugated primary bile acid in the intestine, which is consistent with the in vitro study (4). However, the percentage of DCA in total bile acid was very low (Fig. $1)$.

In another of our reports, no secondary bile acid was detected in the intestine of GB mice monoassociated with either Eubacterium sp. strain 36S (now Clostridium scindens 36S (25), which possesses dehydroxylating activity but no deconjugating activity for taurine-conjugated bile acids in vitro (47), nor Clostridium sp. strain TO-931 (now Clostridium hiranonis (26), which has both deconjugating activity for taurine- or glycine-conjugated cholic acid and high dehydroxylating activity for bile acids (8). Although all of the strains used were colonized in the intestine of the GB mice, no DCA was detected in any of the intestinal contents of the GB mouse group.

There are several reasons for the inconsistency of bile acid transformation by intestinal bacteria in vitro and in vivo. Intestinal conditions such as $\mathrm{pH}$ of the intestinal contents or normal ability of the mucosal epithelium of the intestine may be important factors in transformation of bile acids by bacteria. Koopman et al. $(28,29)$ compared bile acid compositions in various 


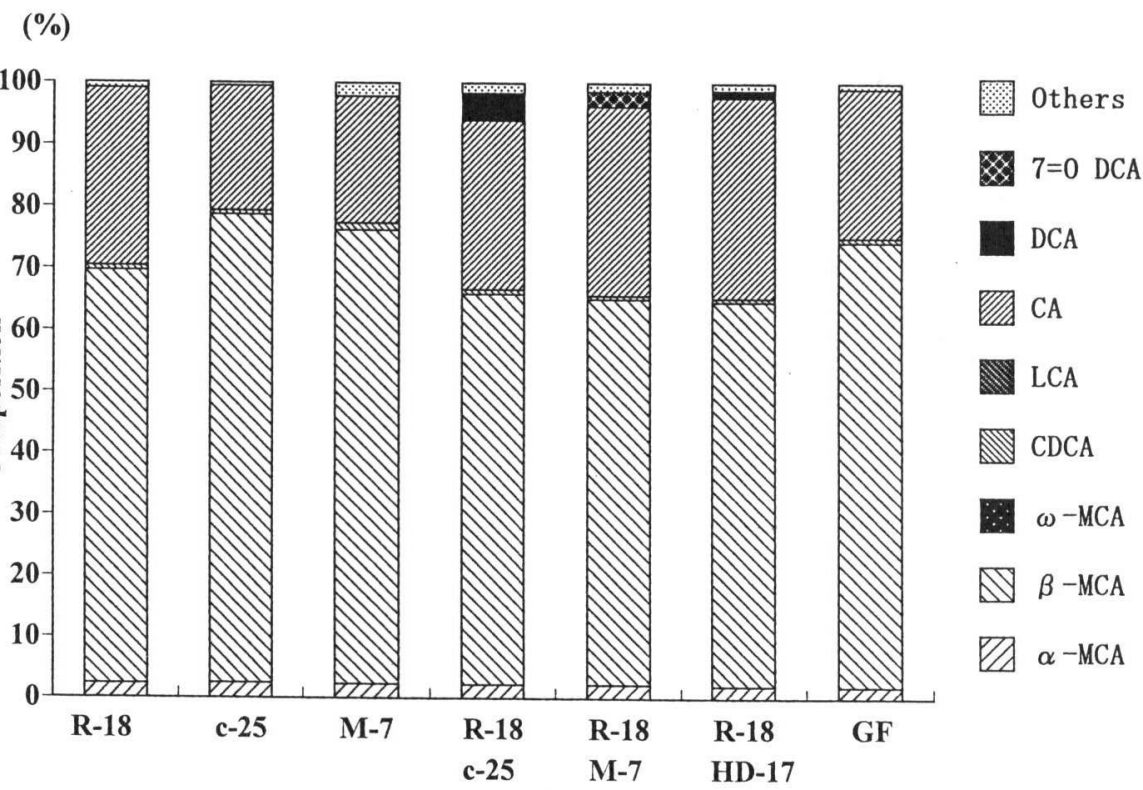

Fig. 1. Bile acid composition in the cecal contents of gnotobiotic mice (Ref. 37).

kinds of GB mice and evaluated normalization using a number of parameters including fecal bile acids. They reported that very complex intestinal microflora was needed to normalize germfree mice. Itoh et al. (22) revealed that a combination of bacteroides, lactobacilli, and clostridia was necessary to convert the intestinal characteristics of GF mice to the normal state. In our study, cecal sizes of the GB mice were more than $5 \%$ of total body weight, far from the normal state.

Another possible reason for the discrepancy in bacterial bile acid transformation in vitro and in vivo is that enhancement of the transformation of microflora in the intestine required cooperative action by different bacteria. Hirano and Masuda (17) investigated the transforming ability of strain c-25, which is enhanced not only by bacteroides in mixed culture, but also by addition to the medium of cell extracts from bacteroides. Takamine and Imamura reported that Bacteroides distasonis strain K-5 has no ability to deconjugate conjugated cholic acid or to dehydroxylate, but this strain can stimulate $7 \beta$-dehydroxylation by other bacteria (46). Although strain K-5 did not stimulate $7 \alpha$-dehydroxylation by other bacteria in vivo in our previous study (38), the possibility of cooperative action by different bacteria in the transformation ability of microflora in the intestine still can not be excluded (50).

In conclusion, the results of these studies indicate that factors other than bacterial transformation of bile acids, such as the intestinal conditions of host animals and cooperation from other bacteria reported by Eyssen and Robben (9), are required to establish a gnotobiotic model presenting secondary bile acids in the intestine.

\section{COMPOSITION OF CECAL BILE ACIDS IN EX-GERMFREE MICE INOCULATED WITH HUMAN INTESTINAL BACTERIA}

GF ICR female mice were orally inoculated with various suspensions or components of human fecal microflora. Samples were obtained from a 47-year-old healthy male donor. In these fecal samples, $99.6 \%$ of the bile acids were deconjugated, and $96 \%$ of the unconjugated bile acids were transformed to secondary bile acids. Fresh feces $(1 \mathrm{~g})$ was immediately placed in 9 $\mathrm{ml}$ of an anaerobic diluent under oxygen-free $\mathrm{CO}_{2}$ gas and a portion was transferred to an anaerobic chamber and serially diluted with anaerobic broth. The $10^{-2}$ and $10^{-6}$ diluted fecal suspensions were prepared for inoculation into GF mice to produce ex-GF mice of group A and group B, respectively. Another $0.1 \mathrm{ml}$ of $10^{-6} \mathrm{di}-$ luted solution was inoculated on Eggerth Gagnon (EG) agar plates (33) in an anaerobic chamber and incubated at $37^{\circ} \mathrm{C}$ for $48 \mathrm{hrs}$. A further $0.1 \mathrm{ml}$ of $10^{-6}$ solution was inoculated on $\mathrm{mEG}$ agar (Nissui, Japan) plates and incubated in an anaerobic steel wool jar filled with $100 \% \mathrm{CO}_{2}$ gas at $37^{\circ} \mathrm{C}$ for $48 \mathrm{hrs}$. From all colonies which developed on each plate, cells were scratched and suspended in anaerobic broth for group $\mathrm{C}$ and group D. The remaining portion of the $10^{-1}$ dilution of human feces was further diluted to $10^{-2}$ and treated with chloroform according to the method of Itoh and Mitsuoka 


\section{Human feces}

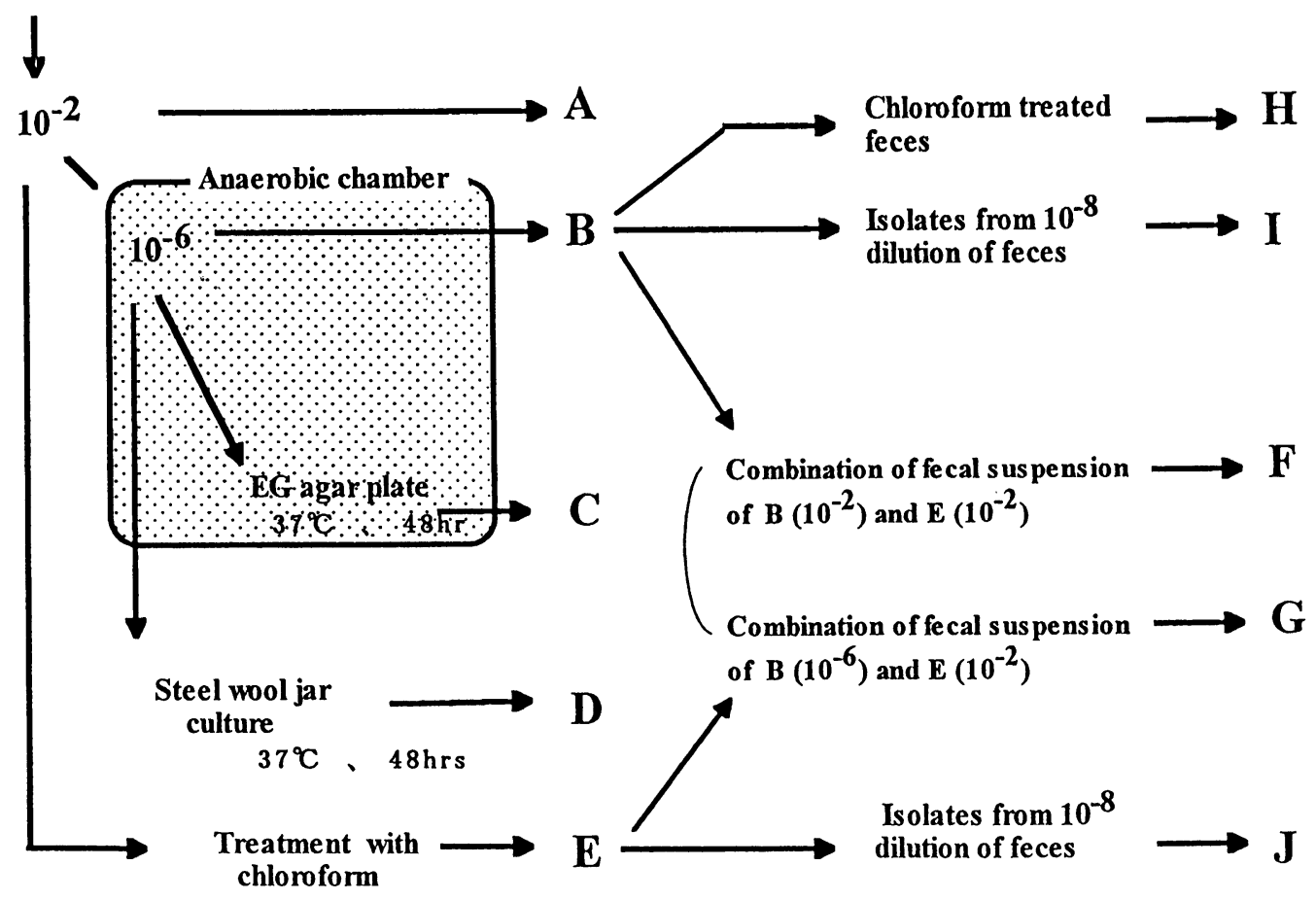

Fig. 2. Production of ex-germfree mice and gnotobiotic mice.

(21) for group E. Two weeks after the inoculation, fecal bile acid composition in ex-GF mice of groups A to $E$ was examined. From the feces of ex-GF mice of groups B and E in which DCA was detected, we prepared further groups of bacterial combinations. For exGF group $F$ and $G$, we prepared a mixed fecal suspension of $B\left(10^{-2}\right.$ and $10^{-6}$, respectively) together with $\mathrm{E}$ $\left(10^{-2}\right)$. Feces of group B mice were diluted to $10^{-8}$ and inoculated on EG agar plates. The colonies that developed were isolated, purified and subcultured. Then the predominant bacterial suspension was inoculated into GF mice for group I. From the feces of ex-GF mice of group $\mathrm{E}$, we also obtained the predominant bacterial suspension for group J. Clostridia from feces of ex-GF group B were also inoculated into GF mice as group $\mathrm{H}$ (Fig. 2).

Among the ex-GF mice in groups A, B, C, and D, bacteroidaceae were detected at the highest levels, and eubacteria and clostridia were also detected in high numbers. Among aerobic bacteria, only enterobacteriaceae and streptococci were detected in the feces of the four ex-GF groups, and staphylococci were detected only in the feces of group A mice. In feces of group $\mathrm{E}$ mice, which were inoculated with chloroform-treated fecal suspension, only clostridia were observed.

In the cecal contents of SPF mice, $44.1 \%$ of MCA was transformed into $\omega$-MCA, but transformation to $\omega$-MCA did not occur in the cecal contents of any group of ex-GF or GB mice associated with human fecal bacteria. This result is consistent with that of Sacquet et al. (41), indicating that human intestinal bacteria have no ability to transform $\alpha$ - or $\beta$-MCA to $\omega$-MCA. It appears that human intestinal bacteria react differently, especially to the CDCA group, from murine intestinal bacteria.

In groups $\mathrm{A}$ to $\mathrm{D}$, the deconjugating ratio was 80 $90 \%$ of total bile acids. However, in group $\mathrm{E}$, in which intestinal bacteria consisted of only clostridia, the percentage of unconjugated bile acids was significantly lower than those in groups $\mathrm{A}$ to $\mathrm{D}(p<0.05)$. The conversion ratios from cholic acid to DCA and from CDCA to LCA were significantly higher in SPF mice than that in ex-GF mice. Although the difference was not statistically significant, the cecal contents of ex-GF mice in group $\mathrm{E}$ tended to show a slightly higher conversion ratio from cholic acid to DCA than those in groups of A, B, C and D (Fig. 3).

DCA was observed in the cecal contents of ex-GF mice in groups of A, B, C, D and E. The percentage of DCA in total bile acids was about $20 \%$, and no significant difference was detected among the 5 groups (Fig. 4). These results indicate that a $10^{-6} \mathrm{fecal}$ dilution of 


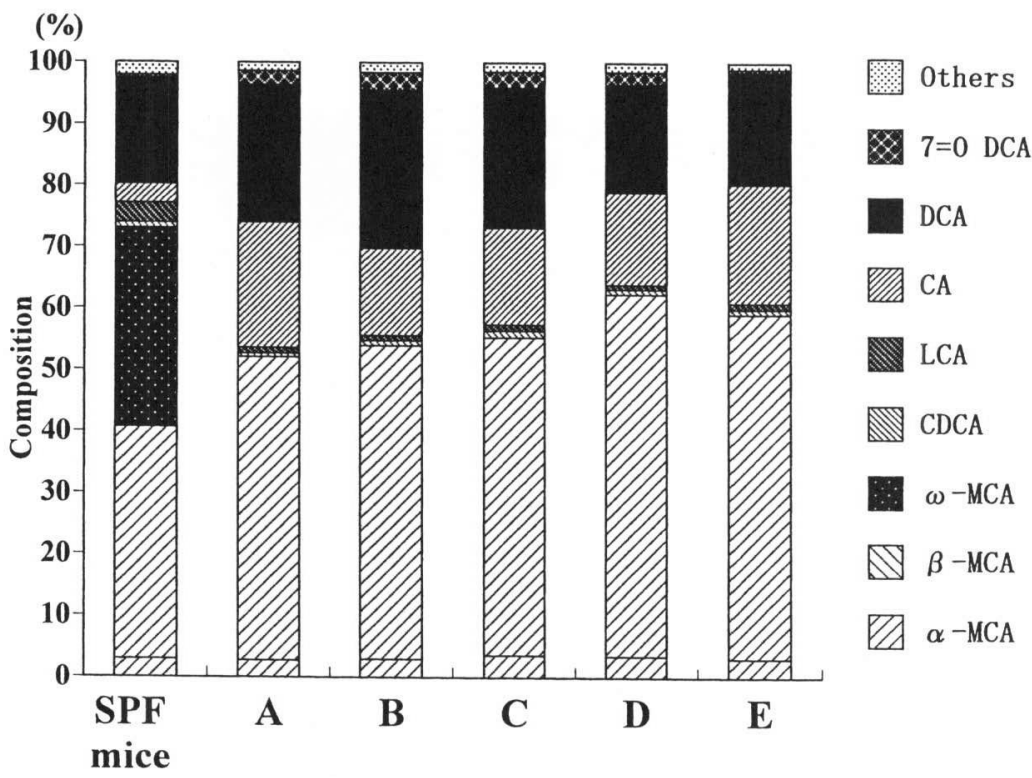

Fig. 3. Bile acid composition in the cecal contents of ex-germfree mice associated with various components of human intestinal flora (Ref. 36).
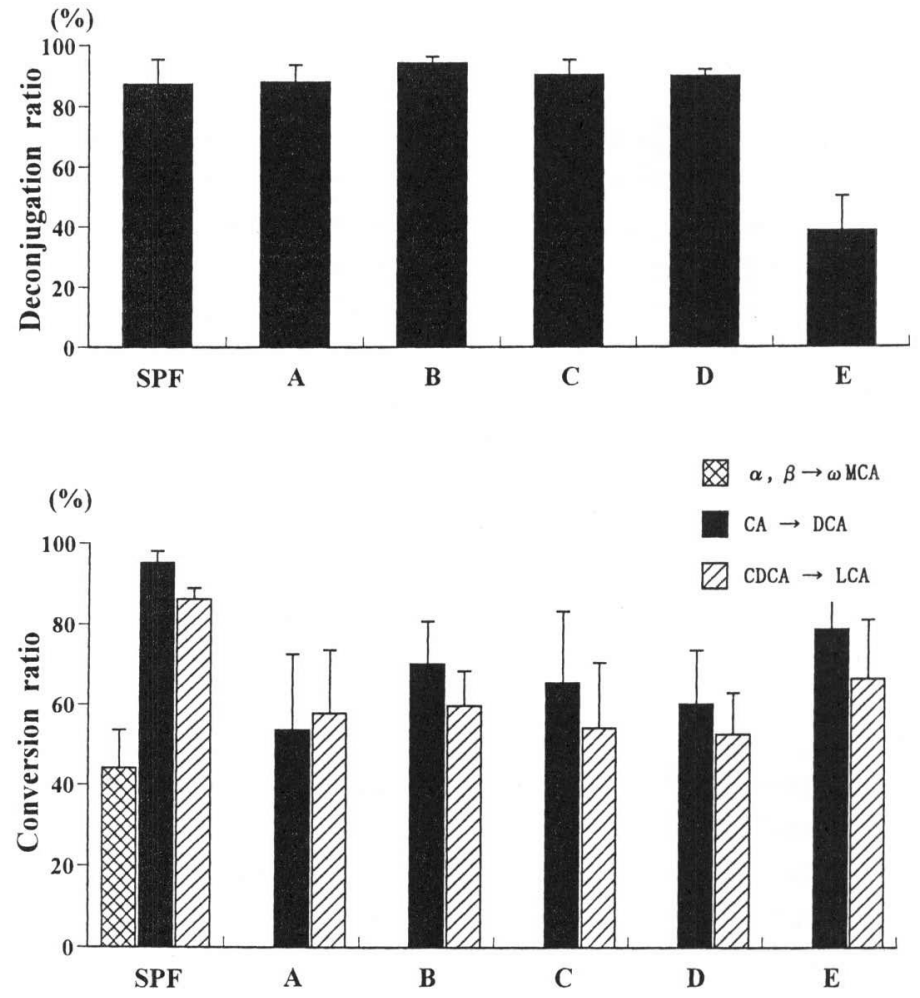

Fig. 4. Deconjugation and conversion ratio of total bile acids in the cecal contents of ex-germfree mice (Ref. 36).

human feces can transform bile acids into the secondary form in the intestines of mice. In the human intestine, the bacterial count reaches the order of $10^{11} \mathrm{CFU}$ per gram. It was suggested that the count of $7 \alpha$ dehydroxylating bacteria in the human feces of this sample may be at least $10^{6} \mathrm{CFU}$ per $\mathrm{g}$ feces, which is a little higher than those in previous reports $(12,43)$. Takamine and Imamura (47) reported that $7 \alpha$ dehydroxylation was detected in dilutions of human feces below $10^{-5}$. In the ex-GF A, B, C and D groups, 


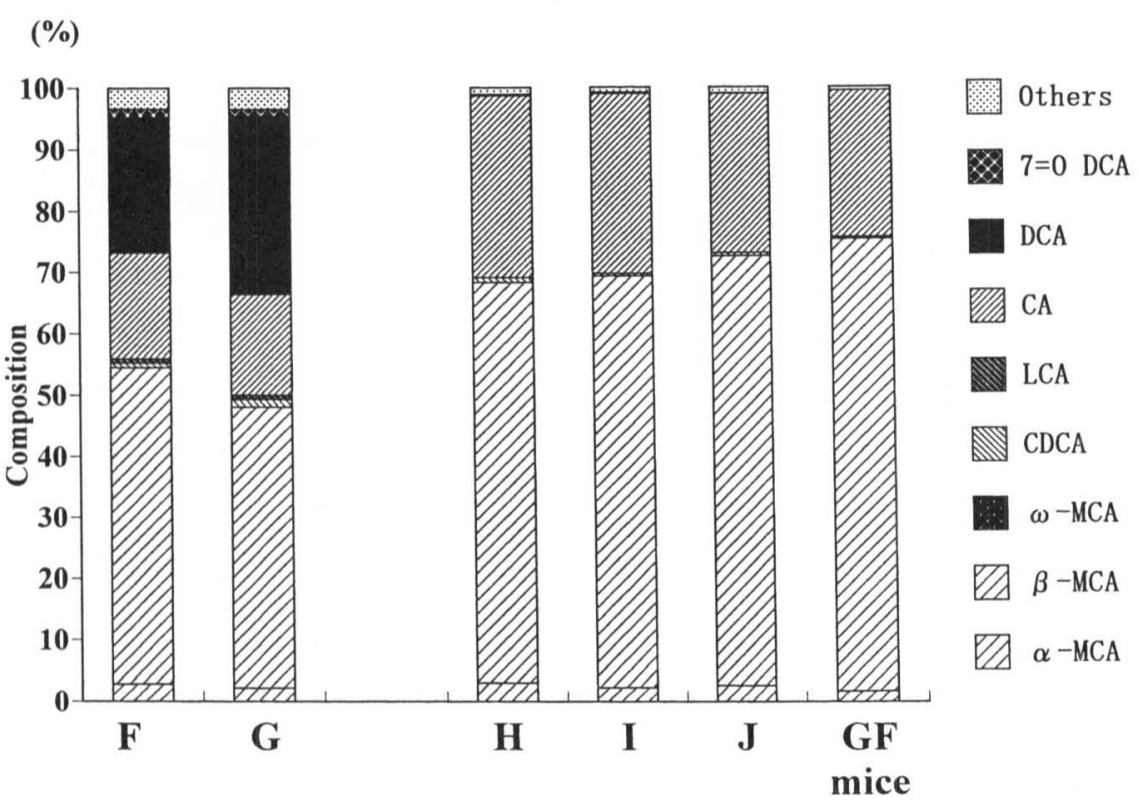

Fig. 5. Bile acid composition in the cecal contents of ex-germfree mice and gnotobiotic mice.

with fecal bacteria comprising mainly anaerobic bacteria, including bacteroidaceae, eubacteria and clostridia, about $90 \%$ of the cecal bile acids were deconjugated. In contrast, in the cecal contents of exGF mice of group E, only $40 \%$ of total bile acids were deconjugated. These results indicate that deconjugation of cecal bile acid mainly depends on bacteria belonging to bacteroidaceae or eubacteria, as reported in in vitro experiments $(6,23,31,44)$, and that bile acid transforming bacteria are culturable on EG agar plates and do not require extreme anaerobic conditions.

In mice and rats, clostridia (fusiform-shaped bacteria) are one of the key bacterial groups for the normalization of GF animals $(22,27)$. Recently, Uchida et al. (49) reported that clostridia isolated from rat cecum play an important role in the formation of secondary' bile acids in rats. In the cecal contents of ex-GF mice associated with chloroform-treated human fecal suspension, DCA was detected at a level equivalent to that of SPF mice, even though the deconjugating ratio was significantly lower than that in other ex-GF mice. It is assumed that clostridia transformed almost all unconjugated cholic acid to the secondary form. It is strongly suspected from the results of our study that clostridia also exert an effect on the formation of secondary bile acids in human intestines.

In the cecal contents of ex-GF mice associated with a combination of feces from $\mathrm{B}$ and $\mathrm{E}$, total and secondary bile acids exhibited higher concentration than those of other ex-GF mice (group F and group G). Fecal flora in these mice consisted of large numbers $\left(10^{11} \mathrm{CFU} / \mathrm{g}\right.$ feces) of bacteroidaceae, followed by clostridia $\left(10^{10}\right.$ $\mathrm{CFU} / \mathrm{g}$ feces) and eubacteria ( $10^{9} \mathrm{CFU} / \mathrm{g}$ feces $)$. However, DCA was not detected in the cecal contents of ex-GF mice in group $\mathrm{H}$, which were inoculated with clostridia from ex-GF mice group B. No DCA was detected in the cecal contents of GB mice in groups I and $J$. They were inoculated with predominant bacteria isolated from ex-GF mice in groups B or E, respectively, in which a considerable amount of DCA was detected in the cecal contents (Fig. 5). One of the reasons for the absence of DCA in groups I and J is that $7 \alpha$-dehydroxylating bacteria are not present in large numbers in the intestine of group B or E, and bacterial combinations isolated from a $10^{-8}$ fecal dilution of a group B or E mouse may not have $7 \alpha$-dehydroxylating activity. Another possible explanation for the absence of DCA in the cecal contents of these mice may be the lower percentage of deconjugated bile acids in group I or Batta et al. (4) reported that prior deconjugation of bile acids is required for further bacterial $7 \alpha$-dehydroxylation in vitro. It was suggested that a large amount of free-form cholic acid is necessary for the concomitant $7 \alpha$-dehydroxylation.

In only a few years, two new species with bile acid $7 \alpha$-dehydroxylating activity were phylogenetically proposed in the genus Clostridium $(25,26)$. Clostridium hiranonis includes strain HD-17 and TO-931, both of which have high bile acid $7 \alpha$-dehydroxylation activity (8), while Clostridium hylemonae has relatively low 
$7 \alpha$-dehydroxylation activity. Furthermore, the strain formerly called Eubacterium sp. VPI 12708 (52), which is known for its high $7 \alpha$-dehydroxylation activity in vitro and the most precise report of the multistep bile acid $7 \alpha$-dehydroxylation pathway (20) together with strain TO-931 (51), was recognized as a member of Clostridium scindens (25). These studies strongly support the hypothesis that clostridial strains are responsible for secondary bile acid formation in the human intestine.

In summary, our results indicate that bacteroides in human feces are the main bacterial group for deconjugation of bile acids, and clostridia may play an important role in $7 \alpha$-dehydroxylation of free-form primary bile acids in the intestine.

\section{PRODUCTION OF GNOTOBIOTE MICE ASSOCI- ATED WITH HUMAN INTESTINAL BACTERIA}

Ex-GF mouse intestinal microflora associated with a human fecal dilution of $10^{-6}$ (group B) showed high deconjugating ability for taurine-conjugated bile acids. We inoculated the feces of these ex-GF mice onto NBGT selective agar plates and isolated 24 strains of bacteria considered to be members of genus Bacteroides. Among these strains, we selected 5 strains with high deconjugating activity for TCA in vitro. The deconjugating ability of TCA in vivo was maintained at high levels when GF mice were associated with these strains. In contrast, selected clostridia from the feces of ex-GF mice group B deconjugated only $10 \%$ of total bile acids.

We also isolated clostridial strains with $7 \alpha$-dehydroxylation activity for primary bile acids from ex-GF mice associated with human intestinal clostridia (exGF mice group E) according to the method of Takamine and Imamura (47) with minor modifications. One loopful of 10-fold diluted mouse feces from ex-GF mice group $\mathrm{E}$ was directly streaked onto $\mathrm{EG}$ agar plates. Finally, we isolated 5 strains of clostridia which showed $7 \alpha$-dehydroxylation activity for CA.

Germfree mice associated with five strains of bile acid-deconjugating bacteroides and five strains of bile acid $7 \alpha$-dehydroxylating clostridia converted TCA into DCA in their intestine, and the transforming activity reflected the results in vitro.

\section{CONCLUSION}

Gnotobiotic techniques make it possible to simplify the complicated ecosystem in the intestine, and to understand the interaction between defined bacteria and the host animal, although we should be aware that there are obvious differences between humans and the animal models. To our knowledge, this is the first report of a gnotobiotic animal model associated with human intestinal bacteria that can convert TCA to DCA. These gnotobiotic mice could be useful in studies of bile acid metabolism by human intestinal bacteria in vivo, and may provide clues concerning the regulation of metabolism by controlling these bacteria in the human intestine.

Acknowledgments. This study was supported in part by a grant from the Programme for Promotion of Basic Research Activities for Innovative Bio-science (PROBRAIN).

\section{REFERENCES}

(1) Archer RH, Chong R, Maddox IS. 1982. Hydrolysis of bile acid conjugates by Clostridium bifermentans. Eur J Appl Microbiol Biotechnol 14: 41-45.

(2) Archer RH, Maddox IS, Chong R. 1981. $7 \alpha$-Dehydroxylation of cholic acid by Clostridium bifermentans. Eur $\mathrm{J}$ Appl Microbiol Biotechnol 12: 46-52.

(3) Aries V, Hill MJ. 1970. Degradation of steroids by intestinal bacteria. II. Enzymes catalysing the oxidoreduction of the 3 alpha-, 7 alpha- and 12 alpha-hydroxyl groups in cholic acid, and the dehydroxylation of the 7-hydroxyl group. Biochim Biophys Acta 202: 535-543.

(4) Batta AK, Salen G, Arora R, Shefer S, Batta M, Person A. 1990. Side chain conjugation prevents bacterial 7dehydroxylation of bile acids. J Biol Chem 265:1092510928.

(5) Bortolini O, Medici A, Poli S. 1997. Biotransformations on steroid nucleus of bile acids. Steroids 62: 564-577.

(6) Chikai T, Nakao H, Uchida K. 1987. Deconjugation of bile acids by human intestinal bacteria implanted in germ-free rats. Lipids 22: 669-671.

(7) Dickinson AB, Gustafsson BE, Norman A. 1971. Determination of bile acid conversion potencies of intestinal bacteria by screening in vitro and subsequent establishment in germfree rats. Acta Pathol Microbiol Scand [B] Microbiol Immunol 79: 691-698.

(8) Doerner KC, Takamine F, LaVoie CP, Mallonee DH, Hylemon PB. 1997. Assessment of fecal bacteria with bile acid 7 alpha-dehydroxylating activity for the presence of bai-like genes. Appl Environ Microbiol 63: 1185-1188.

(9) Eyssen HJ, Robben J. 1989. The indigenous microflora and the intestinal metabolism of cholesterol, bile acids and steroids. In The Regulatory and Protective Role of the Normal Microflora, Grubb R, Midtvedt T, Norin E (eds), Stockton Press, Stockholm, p. 71-88.

(10) Ferrari A, Beretta L. 1977. Activity on bile acids of a Clostridium bifermentans cell-free extract. FEBS Lett 75: 163 165.

(11) Ferrari A, Pacini N, Canzi E. 1980. A note on bile acids transformations by strains of Bifidobacterium. J Appl Bacteriol 49: 193-197. 
(12) Ferrari A, Pacini N, Canzi E, Bruno F. 1980. Prevalence of oxygen-intolerant microorganisms in primary bile acid $7 \alpha$ dehydroxylating mouse intestinal microflora. Curr Microbiol 4: 257-260.

(13) Gustafsson BE, Midtvedt T, Norman A. 1966. Isolated fecal microorganisms capable of $7 \alpha$-dehydroxylating bile acids. J Exp Med 123: 413-432.

(14) Gustafsson BE, Midtvedt T, Norman A. 1968. Metabolism of cholic acid in germfree animals after the establishment in the intestinal tract of deconjugating and 7 alphadehydroxylating bacteria. Acta Pathol Microbiol Scand 72: 433-443.

(15) Hayakawa S, Hattori T. 1970. $7 \alpha$-Dehydroxylation of cholic acid by Clostridium bifermentans strain ATCC 9714 and Clostridium sordellii strain NCIB 6929. FEBS Lett 6: 131133.

(16) Hirano S, Masuda N. 1981. Transformation of bile acids by Eubacterium lentum. Appl Environ Microbiol 42: 912915.

(17) Hirano S, Masuda N. 1982. Enhancement of the $7 \alpha$ dehydroxylase activity of a gram-positive intestinal anaerobe by Bacteroides and its significance in the $7 \alpha$-dehydroxylation of ursodeoxycholic acid. J Lipid Res 23: 11521158.

(18) Hirano S, Nakama R, Tamaki M, Masuda N, Oda H. 1981. Isolation and characterization of thirteen intestinal microorganisms capable of 7 alpha-dehydroxylating bile acids. Appl Environ Microbiol 41: 737-745.

(19) Hylemon PB, Cacciapuoti AF, White BA, Whitehead TR, Fricke RJ. 1980. 7 alpha-Dehydroxylation of cholic acid by cell extracts of Eubacterium species V.P.I. 12708. Am J Clin Nutr 33: 2507-2510.

(20) Hylemon PB, Harder J. 1998. Biotransformation of monoterpenes, bile acids, and other isoprenoids in anaerobic ecosystems. FEMS Microbiol Rev 22: 475-488.

(21) Itoh K, Mitsuoka T. 1980. Production of gnotobiotic mice with normal physiological functions. I. Selection of useful bacteria from feces of conventional mice. Z Versuchstierkd 22: $173-178$.

(22) Itoh K, Urano T, Mitsuoka T. 1986. Colonization resistance against Pseudomonas aeruginosa in gnotobiotic mice. Lab Anim 20: 197-201.

(23) Kawamoto K, Horibe I, Uchida K. 1989. Purification and characterization of a new hydrolase for conjugated bile acids, chenodeoxycholyltaurine hydrolase, from Bacteroides vulgatus. J Biochem (Tokyo) 106: 1049-1053.

(24) Kayahara T, Tamura T, Amuro Y, Higashino K, Igimi H, Uchida K. 1994. Delta 22-beta-muricholic acid in monoassociated rats and conventional rats. Lipids 29: 289-296.

(25) Kitahara M, Takamine F, Imamura T, Benno Y. 2000. Assignment of Eubacterium sp. VPI 12708 and related strains with high bile acid 7alpha-dehydroxylating activity to Clostridium scindens and proposal of Clostridium hylemonae sp. nov., isolated from human faeces. Int J Syst Evol Microbiol 50 (Pt 3): 971-978.

(26) Kitahara M, Takamine F, Imamura T, Benno Y. 2001. Clostridium hiranonis sp. nov., a human intestinal bacterium with bile acid 7 alpha-dehydroxylating activity. Int $\mathbf{J}$
Syst Evol Microbiol 51: 39-44.

(27) Koopman JP, Janssen FG. 1975. The suitability for rats of an intestinal microflora of mice tested under practice circumstances. Z Versuchstierkd 17: 208-211.

(28) Koopman JP, Prins RA, Mullink JW, Welling GW, Kennis HM, Hectors MP. 1983. Association of germfree mice with bacteria isolated from the intestinal tract of "normal" mice. Z Versuchstierkd 25: 57-62.

(29) Koopman JP, Welling GW, Huybregts AW, Mullink JW, Prins RA. 1981. Association of germ-free mice with intestinal microflora. Z Versuchstierkd 23: 145-154.

(30) Mastromarino A, Reddy BS, Wynder EL. 1976. Metabolic epidemiology of colon cancer: enzymic activity of fecal flora. Am J Clin Nutr 29: 1455-1460.

(31) Masuda N. 1981. Deconjugation of bile salts by Bacteroids and Clostridium. Microbiol Immunol 25: 1-11.

(32) Midtvedt T. 1967. Properties of anaerobic gram-positive rods capable of $7 \alpha$-dehydroxylating bile acids. Acta Path Microbiol Scand 71: 147-160.

(33) Mitsuoka T, Sega T, Yamamoto S. 1965. Eine Verbesserte Methodik der Qualitativen und Quantativen Analyse der Darmflora von Menschen und Tieren. Zentbl Bacteriol Parasitenkd Infektionskr Hyg I Orig A 195: 455-469.

(34) Morotomi M, Guillem JG, LoGerfo P, Weinstein IB. 1990. Production of diacylglycerol, an activator of protein kinase $\mathrm{C}$, by human intestinal microflora. Cancer Res 50: 35953599.

(35) Narisawa T, Magadia NE, Weisburger JH, Wynder EL. 1974. Promoting effect of bile acids on colon carcinogenesis after intrarectal instillation of $\mathrm{N}$-methyl- $\mathrm{N}^{\prime}$-nitro- $\mathrm{N}$ nitrosoguanidine in rats. J Natl Cancer Inst 53: 1093-1097.

(36) Narushima S, Itoh K, Kuruma K, Uchida K. 2000. Composition of cecal bile acids in ex-germfree mice inoculated with human intestinal bacteria. Lipids 35: 639-644.

(37) Narushima S, Itoh K, Kuruma K, Uchida K. 1999. Cecal bile acid compositions in gnotobiotic mice associated with human intestinal bacteria with the ability to transform bile acids in vitro. Microbial Ecol Health Dis 11: 55-60.

(38) Narushima S, Itoh K, Takamine F, Uchida K. 1999. Absence of cecal secondary bile acids in gnotobiotic mice associated with two human intestinal bacteria with the ability to dehydroxylate bile acids in vitro. Microbiol Immunol 43: 893-897.

(39) Reddy BS, Simi B, Patel N, Aliaga C, Rao CV. 1996. Effect of amount and types of dietary fat on intestinal bacterial 7 alpha-dehydroxylase and phosphatidylinositolspecific phospholipase $\mathrm{C}$ and colonic mucosal diacylglycerol kinase and PKC activities during stages of colon tumor promotion. Cancer Res 56: 2314-2320.

(40) Reddy BS, Watanabe K, Weisburger JH, Wynder EL. 1977. Promoting effect of bile acids in colon carcinogenesis in germ-free and conventional F344 rats. Cancer Res 37: 3238-3242.

(41) Sacquet EC, Gadelle DP, Riottot MJ, Raibaud PM. 1984. Absence of transformation of beta-muricholic acid by human microflora implanted in the digestive tracts of germfree male rats. Appl Environ Microbiol 47: 1167-1 168.

(42) Stellwag EJ, Hylemon PB. 1978. Characterization of $7 \alpha-$ 
dehydroxylase in Clostridium leptum. Am J Clin Nutr 31: 243-247.

(43) Stellwag EJ, Hylemon PB. 1979. 7alpha-Dehydroxylation of cholic acid and chenodeoxycholic acid by Clostridium leptum. J Lipid Res 20: 325-333.

(44) Stellwag EJ, Hylemon PB. 1976. Purification and characterization of bile salt hydrolase from Bacteroides fragilis subsp. fragilis. Biochim Biophys Acta 452: 165-176.

(45) Takahashi T, Morotomi M. 1994. Absence of cholic acid 7 alpha-dehydroxylase activity in the strains of Lactobacillus and Bifidobacterium. J Dairy Sci 77: 3275-3286.

(46) Takamine F, Imamura T. 1985. 7 beta-dehydroxylation of 3,7-dihydroxy bile acids by a Eubacterium species strain $\mathrm{C}-25$ and stimulation of 7 beta-dehydroxylation by $\mathrm{Bac}$ teroides distasonis strain K-5. Microbiol Immunol 29: 1247-1252.

(47) Takamine F, Imamura T. 1995. Isolation and characterization of bile acid 7-dehydroxylating bacteria from human feces. Microbiol Immunol 39: 11-18.

(48) Takano S, Matsushima M, Erturk E, Bryan GT. 1981. Early induction of rat colonic epithelial ornithine and S-adenosyl-
L-methionine decarboxylase activities by N-methyl- $\mathrm{N}^{\prime}$-nitro-N-nitrosoguanidine or bile salts. Cancer Res 41: 624628.

(49) Uchida K, Satoh T, Narushima S, Itoh K, Takase H, Kuruma K, Nakao H, Yamaga N, Yamada K. 1999. Transformation of bile acids and sterols by clostridia (fusiform bacteria) in Wistar rats. Lipids 34: 269-273.

(50) Van Eldere J, Celis P, De Pauw G, Lesaffre E, Eyssen H. 1996. Tauroconjugation of cholic acid stimulates 7 alphadehydroxylation by fecal bacteria. Appl Environ Microbiol 62: 656-661.

(51) Wells JE, Hylemon PB. 2000. Identification and characterization of a bile acid 7 alpha-dehydroxylation operon in Clostridium sp. strain TO-931, a highly active 7 alphadehydroxylating strain isolated from human feces. Appl Environ Microbiol 66: 1107-1113.

(52) White BA, Lipsky RL, Fricke RJ, Hylemon PB. 1980. Bile acid induction specificity of 7 alpha-dehydroxylase activity in an intestinal Eubacterium species. Steroids 35: 103 109. 